\title{
Paideusis
}

\section{Rethinking the Archetypal Conversation: How Seriously? In What Directions? Who Does the Thinking?}

\section{Walter C. Okshevsky}

Volume 13, Number 2, 2000

URI: https://id.erudit.org/iderudit/1073015ar

DOI: https://doi.org/10.7202/1073015ar

See table of contents

Publisher(s)

Canadian Philosophy of Education Society

ISSN

0838-4517 (print)

1916-0348 (digital)

Explore this journal

Cite this document

Okshevsky, W. (2000). Rethinking the Archetypal Conversation: How Seriously? In What Directions? Who Does the Thinking? Paideusis, 13(2), 43-71.

https://doi.org/10.7202/1073015ar 


\section{Rethinking the Archetypal Conversation:}

How Seriously? In What Directions? Who Does the Thinking? Review-essay of Beyond liberal education: essays in honour of Paul H. Hirst, edited \& with introduction by Robin Barrow \& Patricia White (London \& New York: Routledge, 1993, ix +214 pp.).*

Walter C. Okshevsky, Memorial University of Newfoundland

I

Beyond liberal education offers ten important and thoughtfully crafted essays by authorities of international stature in the philosophy of education, all but one written especially for this much deserved Festschrift for an educational philosopher centrally concerned with a rigorous articulation of the nature and conditions of liberal education. Each addresses some aspect of Hirst's theory of liberal education as it has developed and changed over the years. The text has an Introduction by the editors dealing with Hirst's career and providing an overview of the major themes and problems which concerned Hirst's intellectual life over the years. There is also a very valuable bibliography of Hirst's writings together with a bibliography of critical works compiled by Patrick Keeney. I have used a number of essays from this text in my graduate and undergraduate courses in educational philosophy and have found them to be of significant interest and challenge to students. Highly recommended as a primary or secondary text for courses in the philosophy of education, foundations of curriculum and teaching, and educational leadership and policy amongst others.

One objective of my review is to examine a number of themes of immediate importance to liberal education today. I address the discussion both to academics and to those whose interests in the nature and conditions of liberal education may have been curtailed by past encounters with strictly academic treatments of the subject. As a Festschrift is always a happy occasion and as Professor Hirst has been a major figure over the years in many of our journeys through educational philosophy, this is indeed a happy task.

At a reception for Hirst in Washington 1991, I was pleased to be able to meet him. We shared a story or two about the trials and tribulations of being a philosopher of education in this very postmodem age. I had expected a very serious, perhaps even austere man, in keeping with the tone and substance of much of his written work. Instead, describing in a naturally animated manner the kind of terror that Gilbert Ryle could instill in the soul of a Ph.D. candidate, and did instill in at 
least one of them, Hirst had all the makings of a fine teacher: mind, wit, timing, sincerity, a genuinely sociable and forthright disposition. I also sensed, from that conversation as well as from the address he had just given to the Philosophy of Education Society, a touch of sadness about the reception of his work in education and philosophy of education in particular. As if what was presently happening in education, despite some very positive advances, also signalled a certain loss of something terribly important, a loss which somehow could no longer even be articulated as a loss because of the loss of a language or the absence of a community that was willing to speak it. In this review, I hope to show something of what these losses and gains might look like from a philosophical point of view.

It may be immediately asked: "Well, what would you expect a gathering of philosophers to say about liberal education anyway?" Actually, I find little uncritical or romanticized eulogizing of the value of liberal education for our time in this collection. As its title suggests, the effort is to critically interrogate the contemporary meaning and viability of the early Hirst's ideal of liberal education in our schools and universities in order to determine whether such an education can possibly still be coherently viewed, in spirit if not letter, as that "archetypal idea which ever has been and ever will be, while the nature of man is the same."1 This is as it should be demanded of both friends and foes of liberal education by present social, political, and economic forces. Whether we as educators today find the traditional potions of liberal education a poison for ourselves and our young or a gift of a life-long quest for truth and articulation which we have a moral responsibility to provide or at least offer our young, ${ }^{2}$ we have the obligation to examine honestly and rigorously the conception as an educational ideal and articulate the grounds of our support or criticism.

Hirst's theory of liberal education is one of the most recent and comprehensive versions. Primarily in virtue of that account Hirst is today one of the most highly respected and celebrated living educational philosophers. As these things go, he is also one who has perhaps received more than his fair share of criticism, even vilification, in educational and philosophical domains. Given what he has tried to do, and given the climates of the institutions and fields within which he has had to work over the years, this was only to be expected. Almost every aspect of his work has been subjected to rigorous analysis and critique. ${ }^{3}$ But I think that many who have followed Hirst at least some way in their own travels through the thickets of educational philosophy will agree, if perhaps only grudgingly, with 
Professor Jonas Soltis' view as expressed in his 1979 review of Knowledge and the Curriculum that Paul Hirst "... has one of the most important and potentially powerful philosophical ideas of this century spinning on his potter's wheel, its final shape and function yet to be completed and put to sound educational use." ${ }^{14}$

The dream, however, be it measured in philosophical or in more evidently "practical" terms, never fully materialized. As we shall see below, the pursuit of that particular dream must pass to somebody else. Hirst's constellating educational idea, it needs be said, was not a new one. He tapped an idea of liberal education which had existed in various versions and strains since Plato and Aristotle. Hirst's version abided by the philosophical ideal of the never-ending quest for truth within the different forms in which it is able to reveal itself, an idea spelled out in his article "Liberal education" for the Encyclopaedia of Education in which he lays out the four features of a liberal education as formulated by Aristotle in the Politics. In developing his account, Hirst appealed to what is intuitively a very clear and coherent idea for many: the idea that the knowledge and understanding of the world and ourselves which we pursue within the various theoretical disciplines, and which we rely upon and deploy in a less systematic and informed manner in the practical domains of everyday life, is not all cut from the same cloth but takes different forms. My understanding of DeMorgan's rule or the Pythagorean Theorem is different in kind from the understanding I have of an individual's intentions and motives, be this as expressed within Kipling's poem If or a colleague's wink at a particular moment at a faculty meeting. My sense of moral obligation and responsibility to a community differs again from my knowledge of an empirically given natural or social world. ${ }^{5}$ The essential aim of a liberal education on such an account is to initiate individuals into an understanding and appreciation of the distinctive character of each of the disciplines' manners of formulating our collective experience of the world.

Original to Hirst's formulation of this educational ideal within the field of educational philosophy, and serving most to secure his stature within it, is his account of the manner in which a "form of knowledge" is to be identifed and differentiated from other forms. ${ }^{6}$ Hirst was less concerned with specifying the number of forms of knowledge than with the logically prior task of laying out the logical and epistemological criteria for what is to count as a distinctive and irreducible form of knowledge. He developed a fascinating and elegant theoretical structure which involved a complex verificationist theory of meaning claiming that any form of meaningful experience of a world must be able to take propositional form and that such a propositional form itself entailed both the operation of truth- 
conditions distinctive to the form of meaning in question and a network of logical rules governing the formation and use of concepts, propositions and judgements within that form. Each form was also distinguished by its own set of methods and practical abilities required for the verification/fasification of form-specific knowledge-claims. (Thus practical abilities and practices were always considered defining features of a form of knowledge, even if their status was incorrectly conceived.) The identification of and differentiation between forms of knowledge was a matter of identifying the distinctive character of the truth-conditions operative within any candidate form of knowledge. Consequently, a liberal education was to be "fairly and squarely" based not on sectarian interests, or the dictates of government legislation, or the latest curriculum fashion, or on the present and particular predilections of students, but rather on a comprehensive effort of "initiating" students, getting the students "on the inside of" the pursuit of the different forms of knowledge, as Peters and Oakeshott would put it. The core of this education was intellectual; other dimensions of personhood were deemed to depend upon the cognitive for their own rational development.

The theory was a philosophically sophisticated and difficult one. It generated many misreadings: some failed to differentiate between conceptual and empirical ways of classifying "knowledge," but condemned it nontheless for its "apriori conception of rationality;" others read Hirst to be claiming some entailment from the logic or epistemology of a discipline to actual practices of its teaching or learning despite Hirst's repeated claims that the relationship between philosophy and educational practice was more involved and less direct. Others, enamored by "childcentered" pedagogies, claimed they taught students rather than disciplinary subjects and found talk about the "objective existence of disciplines" to be too metaphysically remote from their professional task of addressing students' firstorder wants, experiences and needs. Within philosophy of education itself, many pounced on one or another aspect of a theory which Hirst himself admitted was tentative and needed much further analysis and clarification. These discussions were often pitched at a rarified level of abstraction, and many wondered how the task of educating the young could be benefitted by transcendental arguments and talk of truth conditions.

By the end of the $70 \mathrm{~s}$, it was evident that criticisms and trends in the academic and general culture were to lead to fundamental revisions in the character and stature of educational philosophy. Staying simply with philosophical currents, change was fuelled by a growing number of chinks in the hegemony of the analytic tradition in philosophy in general. Both student and scholar began to hear repeated 
calls for "the end of epistemology," "the end of philosophy," "a postmodern vision," a "hermeneutic vision" and turned to Bernstein, Rorty, Gadamer, Taylor, Habermas, Foucault, MacIntyre and/or Bourdieu for alternatives to strict linguistic-conceptual analysis. The "new" sociologists of education also challenged fundamental premises of the Peters-Dearden-Hirst orthodoxy. Making recourse to the writings of Marx, Freire, Maxine Greene, Michael Young, a de-transcendentalized (Schutzian) version of Husserlian phenomenology called "ethnomethodology," Bowles and Gintis' "reproduction theory," and recent developments in "social constructivist theory", the "intellectual/political hegemony" in educational theory and philosophy was quickly coming to a close. Today, as we shall see in examining Hirst's essay, the rebirth of an Aristotelian approach in education and philosophy strives to cast many of Hirst's "rationalist," individualist" and "liberal" assumptions onto the side-lines. But as even a cursory look at Keeney's compilation of secondary works on Hirst reveals, that "hegemony" created a significant legacy, one we are certainly free to reject but not to responsibly ignore. And that in itself is a most definite mark of distinction.

\section{III}

"Education, Knowledge and Practices" is Hirst's most recent statement of his views on liberal education and on his original formulation of it through the forms of knowledge theory. After examining what he considers to be some of the major "rationalist" and "'utilitarian"' trends and assumptions, fads and foibles, characterizing the philosophy of education in the $60 \mathrm{~s}$ and $70 \mathrm{~s}$, the essay culminates with a number of recantations and a revised view of the nature and aims of a viable form of liberal education. The dominant influences on Hirst are now no longer Peters, Ryle, and Wittgenstein, but rather Kekes, MacIntyre, Taylor and White.

The "turn" here needs to be carefully diagnosed. While the logic and epistemology undergirding the identification of forms of knowledge remains mostly intact, Hirst now takes "a different view as to how these elements are best construed." In line now with White's position regarding the necessity of privileging ethical value over knowledge and understanding within justifications of educational aims, ${ }^{8}$ Hirst no longer sees the foundations or even primary goals of education within an initiation into disciplinary-specific frameworks of objective knowledge.? Jettisoned also is the ideal for students to be educated "directly" in the theoretical disciplines themselves. ${ }^{10}$ Recourse is no longer made to reason for the possibility of disengaged objectivity and autonomous individualism. Emphasis is now on practical forms of "action and experience" comprehended as categories of philosophical and educational analysis which are no longer taken as equivalent with forms of 
knowledge. The former are now posited to be more conducive to an appreciation of the particular character of an agent's socially originating and socially sustained engagement within the networks of practices she is heir to as member and critic: practical knowledge is now posited as more fundamental than theoretical knowledge. What was once to be "fairly and squarely" based on the nature of knowledge itself, ${ }^{11}$ what was once an "achievement of those most central objectives of all, the acquisition of knowledge and rational belief, without which the development of rationality in any wider sense is logically impossible"12 is now framed within the more comprehensive and explicitly Aristotelian ideal of "a flourishing life" with its "priority of personal development by initiation into a complex of ... practices." 13

Let us take a closer look at this metamorphosis of the forms of knowledge theory into a "more Aristotelian approach" to education and rationality. The question I read to motivate Hirst's adoption of this new approach is whether that theory had correctly delineated the logical status and educational significance of theoretical knowledge in its relations to (other) human practice(s). May it not be the case that the pursuit of reason through the different disciplinary forms of knowledge is best comprehended, in both logical and educational terms, as initiation into relevant sets of social practices, where "social practices" are understood, much in line with Alasdair MacIntyre's account, to comprise entire holistically integrated complexes of knowledge, desires, attitudes, dispositions, feelings, virtues, skills, judgement, criteria of success for actions and projects, moral and prudential values and inter-personal relationships? Answering this question, Hirst concludes categorically: "we must shift from seeing education as primarily concerned with knowledge to seeing it as primarily concerned with social practices." 14 I find two major reasons offered by Hirst for this required shift: 1) the need for a broadening of the fundamental aims of education to include the above elements of a social practice within its guiding conceptions of personhood and the good life, and 2) a reversal of the thesis of the logical primacy of theoretical over practical knowledge and reason. Both of these premises now function as correctives within the intention to overcome what Hirst terms the traditional "rationalist" picture of theoretical and objective reason so characteristic of the Analytic philosophical movement in education at its crest.

Any measure of the coherence and success of Hirst's new premises and overall project must be made in cognizance of those claims and assumptions Hirst now wants to repudiate. We can identify three of these as presented in the essay: 1) a stipulative conception of liberal education requiring direct and necessary initiation 
into theoretical (academic/disciplinary) forms of knowledge argued to be "ultimately fundamental to everything else in education;" 2) a commitment to the transcendental status of reason with its corresponding effort to reconstruct and deploy "principles independently derived from the nature of reason;" 3) the assumption of "a high doctrine of the powers of detached reason to both determine and motivate the good life" - a doctrine operative with particular salience in the assumption of a universally valid framework of social and political principles available to the rational consent of all. Each of these "rationalist" views or hopes Hirst now believes to trade in one way or another upon a mistaken assessment of the powers and hence the status of epistemic capacities for objective rationality:

Reason can put into propositional form only what is necessarily a limited element in any situation, trading in any given instance in categories that necessarily strip practical realities of all their other aspects, exclude unique particularities, and ignore all tacit considerations. ${ }^{15}$

Moreover, Hirst now avers that reason is more accurately construed as a capacity deployed in integration with the affective and conative dimensions of our personhood. And it is precisely the educational significance of this recognition of the holistic integrity of personhood that the shift to social practices is meant to secure and foster.

We would misunderstand both the nature and the source of this shift to social practices were we to see it as the result simply of an expanded conception of personhood in pursuit of "the good life" now more comprehensively understood. As I read it, what yields that educational view is the premised shift in Hirst's conception of the logical structure, the presuppositional form we can say, of the relation between theoretical and practical reason. It is his examination of the nature and status of theoretical reason in relation to human agency that yields the subsequently re-assessed and now broadened educational imperative:

The main error in my position was seeing theoretical knowledge as the logical foundation for the development of sound practical knowledge and rational personal development. ... I now consider practical knowledge to be more fundamental than theoretical knowledge, the former being basic to any clear grasp of the significance of the latter. ${ }^{16}$

To now premise the logical and educational priority of the practical over the theoretical is to claim the nature of theoretical reason to presuppose the constitutive features of practical reason as necessary conditions of its possibility, and to claim that the practically-oriented features of our agency provide the necessary motivational force for the operation of reason. It should be asked here what it is precisely that theoretical reason, indeed reason itself, must presuppose in being 
necessarily conditional in these two ways upon practices and practical reason. It appears to be the case for Hirst that reason across its forms is originally and necessarily practical in that its functioning throughout theoretical and practical contexts displays "an anchorage of values in wants and satisfactions." 17 Reason is originally practical reason because it empirically displays such motivational anchorage. Our rational pursuits of theoretical knowledge logically presuppose practical knowledge in virtue of the necessity and primacy of wants and satisfactions anchoring the possibility for reason itself. Hirst's turn accepts both premises.

It is now in light of this "anchored" view of reason that rationality, the good or flourishing life, holistic personhood, the institutions and relationships fundamental to liberal democracy, and education are all re-conceived and analysed via the prism of desires, wants and satisfactions. Reason is logically and empirically practical reason. Practical reason operates in order to secure present and extend future satisfactions. Consequently, we are now required to recognize reason in the pursuit of true belief and justifiable action to itself comprise a satisfaction - a satisfaction as fundamental to our individual personhood and the collective good life as any other satisfaction or want. ${ }^{18}$ We must now view rationality as a desire to be satisfied "within and alongside other wants and satisfactions;" the theoretical pursuit of reaching agreement on knowledge-claims, moral judgements, etc. is now itself but an instance of our "seeking satisfactions" within the good life. ${ }^{19}$ Objective, propositional knowledge secured by theoretical reason also naturally falls into place:

[T]he primary propositions that reason delivers are generalizations concerning successful and unsuccessful practice. ${ }^{20}$

[Propositional knowledge is] the product of practices that seek a particular form of satisfaction. It is that satisfaction which arises from the successful exercise of our given capacities to share conceptual schemes in which there can be agreement in judgements of truth. ${ }^{21}$

That reason in whatever form is empirically and logically practicallyoriented, that in order to be practical reason must be motivated by the satisfaction of some want or desire as an end, and that theoretical reason logically presupposes practical reason in that the former is structurally tied to wants and desires are three central claims now anchoring Hirst's second imperative for us: "[W]e must take seriously the idea that reason is ... always directed by our interests and is of its nature practical."22 It remains unclear to me why this imperative is presented with greater reticence than is the above imperative exorting us to view social practices as comprising the fundamental and primary educational aim. Hirst renders this latter 
concluding claim in strict categorical terms and yet our conclusions are only as compelling as our premise(s) allow. How seriously we are to consider adopting the view that reason is always "directed by" our interests, comprehended as the satisfaction of wants and desires, is a question left as open to argument as the idea that what makes reason "practical" is its subservience either to the end of satisfying some extant interest(s) or to the end of expanding the range of possible satisfactions through the development of strategies and means for their more effective and efficient attainment. I find Hirst's account here to be ambiguous and ambivalent on such matters. (His explicit reservation in the very final sentence of the essay should be duly noted.)

The ambiguity and ambivalence here may be attributable in part to Hirst's clear scepticism and distaste for a burgeoning "utilitarian" metanarrative in philosophy and education which he fears may end up underestimating the power of our rational capacities in deliberation upon the ends of the good life and undervaluing their efficacy in motivating us to actually live it. As well, the thesis of an always desiring reason intends to counter simultaneously a false dualism of reason and desire, which Hirst finds continuingly and paradoxically operative within recent "utilitarian" views, ${ }^{23}$ coupled with an illegitimate subjectivism which deems judgements regarding the good to be grounded in nothing more than personal subjective states. ${ }^{24}$ Both views, Hirst correctly notes, ultimately conspire to misrepresent the enterprise of education as but a purveyor of knowledge, skills and dispositions as commodities having immediate instrumental value. ${ }^{25}$

What I would very much like to see Hirst pursue and articulate further are his views on how the logically primary and constitutive role of practical agency within theoretical reason is able to surmount the subjectivism he rightly warns us of and this without falling prey to the dualisms he identifies and without inveighing once again the "transcendentalism" of the forms of knowledge theory he now wishes to eschew. Central to this task may be an explanation of how it is that the original "anchorage" of theoretical reason in the wants, desires and interests of practical agency - as evidenced in 1) the individuation of objects, situations and events posited within our conceptual schemes and 2) in the grounding of propositional knowledge within warrants governed and assessed by pragmatic criteria of success for actions ${ }^{26}$ - is still able to secure that form of "critical reflection" Hirst continues to hold to be "crucially important for all."

But worthwhile education conceived in these terms requires initiation into the practices of critical reflection on the fundamental substantive practices it basically involves, not merely immersion in these basic practices. ${ }^{27}$

I believe that Hirst's prospects in this task are promising, especially if he is able to 
successfully differentiate between the different kinds of "satisfactions" involved in forms of the true and the good agents are capable of pursuing. Practices of the pursuit of truth, be they "substantive" or "second-order," would seem to comprise a highly distinctive kind of enterprise for agents to pursue, if only because truth is not itself affected by our wants, desires and personal or collective interests. Meaning, the intelligibility of things we posit as objects of theoretical examination and analysis would seem to be more closely tied to our agency in the world than is truth. ${ }^{28}$

A more fundamental matter concerns the truth of the premise that practical reason is both logically and motivationally tied to desires and wants. But does practical reason, in order to be "practical" necessitate any desire or want in order to be motivationally efficacious? Is the human will really an all-too-Humean slave to our desires? Would the possession of a belief not be sufficient to move one to action, a belief in the form of an imperative? Or do these questions somehow perpetuate once again one of the dualisms that Hirst wants to avoid? Answers here cannot be given without addressing what is perhaps one of the most powerful and comprehensive accounts of practical reason we have available to us today: Kant's ethics. ${ }^{29}$ Hirst, along with John White, Bernard Williams and Alasdair Maclntyre amongst others assume a position on the nature and conditions of practical reason differing markedly from Kant's. Explicit attention to the sources of disagreement here would, I believe, serve to fruitfully clarify Hirst's present positions further.

The turn away from epistemologically-centered conceptions of rationality and liberal education to a more comprehensive vision of our holistically-integrated capacities for human agency was already evident in his 1983 essay in Educational theory and its foundation disciplines, ${ }^{30}$ when he wrote that the most pressing problems education faces today are not primarily epistemological or logical in character but rather ethical and moral - problems embedded within the social, political, and economic practices environing and infiltrating our schools and universities. But the question remains: Whether the relationship between the early and the later (last?) Hirst is not in some ways similar to the relationship between the early and the later Wittgenstein; whether some of Hirst's disappointment is not in some way tied to our present inability or unwillingness to understand an idea which, within its own circumscribed limits and context, may be perfectly in order.

I turn now to a consideration of some of the contributions to this Festschrift which I believe are of direct relevance to Hirst's original and revised projects. There are three essays in this collection which I cannot address adequately here at this time: "Paul Hirst's structure, or, the uses and abuses of an overworked concept" by 
Denis C. Phillips; "Wittgenstein's speculative aesthetics in its ethical context" by R. K. Elliott, and "The arts, well-being and education" by John White.

\section{IV}

Pring's "Liberal Education and Vocational Preparation" offers a valuable and quite comprehensive statement of some of the major contemporary social, moral, and economically based criticisms of liberal education together with an indication of the kind of agenda Pring believes is required for examining their validity. The essay is required reading for anyone deeply concerned about the accuracy of the diagnosis of the modern condition of knowledge as depicted in the following words of Lyotard:

The old principle that the acquisition of knowledge is indissociable from the training (Bildung) of minds, or even of individuals, is becoming obsolete and will become ever more so. The relationship of the suppliers and users of knowledge to the knowledge they supply and use is now tending, and will increasingly tend, to assume the form already taken by the relationship of commodity producers and consumers to the commodities they produce and consume - that is, the form of value. Knowledge is and will be produced in order to be sold, it is and will be consumed in order to be valorized in a new production: in both cases, the goal is exchange. Knowledge ceases to be an end in itself, it loses its 'use-value'. ${ }^{31}$

In order to flesh-out that clear contrast between liberal education and vocational preparation which many contemporary criticisms assume, Pring initially develops his account of liberal education not in its Socratic version as the unified development of intellectual and moral virtue but rather in an undiluted "pure form" with its focus on intellectual excellence, following Oakeshott, Newman, and the early Hirst. Five major characteristics of liberal education today repeatedly targeted for criticism by "the vocational challenge" are identified.

1) A liberal education is an initiation into forms of understanding the sole purpose of which is the rendering intelligible of the truth about the world and our place in it. The pursuit of such truth is an intrinsic end of liberal education and requires no external justification.

2) Because the engagement with liberal education is an initiation into a conversation with the history of the mind or civilization itself, it is difficult to establish specific educational objectives for such learning and to evaluate the learning that may have been achieved. The learning involved is a learning of habit, disposition, judgement, imagination, and perspective which is not readily amenable to a "product/output" orientation modelled on the "performance objectives" criterial for the transmission of skills and technical competencies. 
3) Accountability within liberal education is immanently defined: "performance indicators" for learning and teaching that may be formulated by, say, government or industry, do not challenge the authority of those within schools and universities who teach the liberal disciplines and have little practical effect on decisions concerning curriculum or evaluation. The strictly academic criteria immanent within the disciplines themselves reign supreme.

4) Liberal education proceeds best at a distance from everyday practical conflicts and problems. Perhaps one of the most eloquent contemporary statements of this requirement is given by Michael Oakeshott who sees a university education as one which "works undistracted by practical concerns; its currrent directions of interest are not determined by any but academic considerations..." ${ }^{\text {32 }}$

5) Liberal education promotes only intellectual virtues and focusses little on the fostering of virtues of moral character or of economic well-being such as competition and enterprise.

Pring clearly articulates each of these traditional features of the pure form and lays out four major criticisms of liberal education comprehended in this pure form: its exclusivist and elitist character, its insousiance towards present economic exigencies, its irrelevance to societal needs, and what we may call its "immanent" locus of authority and accountability which appears to shun a responsibility for meeting criteria of accountability originating outside the self-imposed and selfmaintained jurisdictional bounds of academic institutions. Pring's assessment of the vocational challenge is that it is of sufficient coherence and warrant to merit serious re-thinking of the idea(l) of liberal education in light of four central features: 1) aims and values, 2) structure and content of knowledge, 3) virtues and dispositions to be promoted, 4) authorities to be obeyed. While at times it appears that Pring rises to the challenge by simply vocationalising liberal education - i.e., recommending an expansion of the conversation to include students' voices articulating their own biographies, expectations and interests in alien cultural traditions, employers' voices reminding the young of the needs and realities of the vocational world, and voices from the wider community making claims on social and moral issues - his analyses are actually more subtle and complex. $\mathrm{P}$ r i $\mathrm{n} g$ maintains that if the required compromise and reconciliation of differences along these lines is to be achieved, then we will need to give up on the hard-and-fast distinction between vocational education and liberal education in its pure form. For to invest in this sharp separation is for the reconciliative task to be formulated as but a simple additive effort at liberalising vocational education and vocationalizing liberal education. ${ }^{33}$ This will not do within Pring's agenda for what is required is not 
a combination of two educational integrities in themselves already independent and self-sufficient but rather a genuine synthesis of elements. If I'm reading Pring right, the synthesis he is after would combat the additive and separatist view operative in, for example, Nussbaum's claim that "[p]eople who have never learned to use reason and imagination to enter a broader world of cultures, groups and ideas are impoverished personally and politically, however successful their vocational preparation." ${ }^{34}$ Pring's sought-after synthesis must simultaneously acknowledge legitimate distinctions between liberal and vocational education while also recognize that the same learning experience/activity/texts can be either liberal or vocational depending on the perspective from which it is being pursued or examined. ${ }^{35}$ Pring's agenda is consequently to examine each of the above four features in the attempt to identify possible vocational dimensions of liberal education and possible liberal dimensions of vocational education.

I find Pring's task somewhat reminiscent of Peters' view that reading the difference between liberal and vocational learning as one between the pursuit of knowledge for its own sake/its own intrinsic value and the pursuit of knowledge for practical ends is doomed to fail due to the coarseness of the latter distinction in identifying the attitude of the learner towards the knowledge being acquired. ${ }^{36}$ For Peters, it is in the context of the acquisition of knowledge (rather than of the advancement of knowledge) that this latter distinction breaks down since practical knowledge/learning can itself be pursued for its own sake. The distinction that Peters believes should continue to hold in characterizing liberal education, however, is one between practical learning pursued for its own sake (in a liberal manner) and an instrumentally-directed learning motivated by such corrupting influences as envy, greed and ambition. ${ }^{37}$ As Chandra Mohanty puts it, liberal education degenerates when it is pursued as "the mere accumulation of disciplinary knowledges that can be exchanged on the world market for upward mobility."138 Pring, like Peters, does well in reminding us that whether we are pursuing disciplinary knowledge, or practical knowledge, or a synthesis of the two, the running of a ship requires sailors whose primary concern is the art of sailing. No other intrinsic or extrinsic aim is more valuable for safely arriving at our educational destinations. I find much of value in Pring's attempts at reconciliation and his efforts are often successful once certain traditionally defining characteristics of a liberal education are reconceived or eliminated. Also instructive is his critical attentiveness to the "vocationalizing and economizing of language" within present educational contexts - uses of language serving to pre-structure the issues and understandings within a language of audits, performance indicators, cost- 
effectiveness of curriculum delivery, quality assurance, competency-based objectives, value added, inputs and outputs, usefulness.

Cooper's "Truth and Liberal Education" examines the different conceptions of the nature of truth grounding the early Hirst's theory of liberal education and Plato's Republic. A comprehensive "conception of truth," on Cooper's account, is required, among other things, to explain why truth is a desideratum. What is the point of seeking the nature of truth as opposed to questing after that which is true? And what's the point of asking that, one may ask. Cooper argues that a conception of truth should shed light on a fundamental imperative to which any view of the nature and purposes of education (and, indeed, life itself) needs to respond: "the fulfilled human existence." His essay is an intriguing attempt to show how a conception as ostensibly removed from contemporary education as is "truth" can, once appropriately epistemologized, be reconstructed to bear a determinate version of a meaningful life as the desideratum of a liberal education. Hirst's conception of truth is developed as a version of "waranted assertability" grounded in a community's socially sustained agreement on what are to comprise standard conditions for the correct applicability of language to the given. This "given," as both Hirst and Wittgenstein emphasized, is to be found within the realm of human experience and socially constructed symbol systems. It is not the ground of truth as construed under the auspices of Greek metaphysical realism. Cooper's account of the correlative conception of fulfilled human existence is, I find, much like Taylor's "affirmation of the ordinary life. $" .{ }^{39}$ fulfillment is "immanent" within everyday life, i.e., fostering and pursuing such everyday community values and individual aspirations as creative work, fellowship and friendship, sexual joy, the pursuit of knowledge and understanding, everyday coping with the mundane problems given within our being-in-the-world. For Cooper's "Immanentists," the pursuit of this form of life is at bottom the pursuit of fulfillment through membership and participation within the on-going language-games and social practices one finds oneself surrounded by. ${ }^{40}$ The quest for fulfillment and happiness here fortuitously converges with acting in accordance with those public criteria of intelligibility and following those procedures of inquiry which Hirst claimed to condition the possibility of the forms of knowledge and understanding. Immanentists, on Cooper's account, do not simply adopt a posture of Rortian insouciance towards the competing Platonic "transcendental" conception and ideal of truth. Rather, they find there to be "something at once alienating and rather pathetic in the attempt to step outside the framework of public criteria" ${ }^{41}$ - and this because we lose that Hirstian "pattern and order," that skill and partnership called for by "the conversation of mankind," which 
engagement within the practices of one's community makes possible and sustains. Kierkegaards' Abraham, Cooper tells us, is an example of the man who turns away from what Wittgenstein referred to as "the scene of our language game" - a refusal by which

he not only sets himself apart from the others, but in doing so debars himself from achieving that self-mastery which requires a smooth and skilled, 'patterned and ordered' participation in the physical, moral and intellectual practices of his society. ${ }^{42}$

What ultimately raises the Immanentist's ire in the competing Platonic conception of truth is that

[t]ruth is a desideratum independently of the political and psychological benefits which knowledge of it furnishes. It is desirable because, in coming 'in contact with truth', a person transcends the 'merely human', achieving the ultimate goal of desire - an identity or correspondence with the divine and the immortal. ${ }^{43}$

Cooper goes on to outline what in his mind constitute intractable difficulties for any theory of liberal education which seeks to ground its vision in a conception of truth originally predicable of objects in the cosmos rather than of statements and beliefs, one for which a vision of the Form of the Good is a possibility only for those able to eschew the "world of change" and its inadequate form of truth, and one which promises an immortality of the divine in exchange for all that is "merely human" i.e., the sensuality of the body, the contextualization of thought within the sociohistorical, the giveness of human perceptual and cognitive apparatus. ${ }^{44}$

I find Cooper's reading of Plato to be somewhat extreme and one-sided. Ilham Dilman argues for a Wittgensteinian corrective to Plato's conception of mathematics which recognizes the ways in which social norms of description actually operate in mathematical calculation. ${ }^{45}$ Dilman draws some of the consequences for a re-interpretation of the doctrine of Reminiscence which is able to deal with a number of problems besetting Plato's metaphysical realism and doctrine of Truth. ${ }^{46}$ Such an effort is in keeping with Cooper's attempt to link truth to a vision of the good life able to function satisfactorily as an ideal of liberal education. But a caveat of another sort is in order. This is that the value of Plato's Republic for liberal education may be precluded by a highly constricting reading of Plato's "transcendentalism" - one that attenuates our understanding of Plato's conception of the relationship that should hold between "the finest spirits among the philosophers" and the community which comes to know how to make use of them.

My reading of The Republic's vision of making contact with Truth (the Form of the Good) differs fundamentally from Cooper's. As I see it, it is an ideal which exorts the development of personal virtues and social dispositions which are 
what they are and can only be what they are in this world. A soul possessed of "good memory, quick apprehension, magnificence, grace, friendship, restraint and gentleness in physical and emotional passion" - one, in other words, "akin to truth, justice, bravery, and sobriety"47 - makes little sense in an ethereal, other-worldly realm, devoid of social and political dimensions. These virtues require "the rough ground" that provides those occasions for success and failure, for courage and evasion in the face of oneself and others, that enable the possibility for the achievement of authentic virtue and the overcoming of vice. But also, does not Plato agree with Socrates that "making contact with Truth" comprises an epistemic ideal which is equally a moral ideal - one addressing one's obligations to the community and the state? We need here to remember the obligation which Socrates felt in refusing to escape what for him was to be the state's final decree. It is an obligation also expressed in the following words:

You have again forgotten, my friend, ... that the law is not concerned with the special happiness of any class in the state, but is trying to produce this condition in the city as a whole, harmonizing and adapting the citizens to one another by persuasion and compulsion, and requiring them to impart to one another any benefit which they are severally able to bestow upon the community, and that it itself creates such men in the state, not that it may allow each to take what course pleases him, but with a view to using them for the binding together of the commonwealth. ${ }^{48}$

I want to suggest here that Plato's presentation of the Socratic ideal of an integration of the soul with the order and beauty of the cosmos is not at all a flight into the darkness of abstraction nor one into the rarified heights of an anticommunal, mystifying and unattainable sense of fulfilled human existence. The erotic attraction of the timeless and absolute is more accurately read as a turning away from self-centered practices of conditionalizing, compromising and relativizing the Good within one's everyday being-in-the-world. I believe this is the message that Plato has Socrates say in his statement that the person who

fixes his gaze upon the things of the eternal and unchanging order ... [and sees] that they neither wrong nor are wronged by one another, but all abide in harmony as reason bids, will endeavour to imitate them and, as far as may be, to fashion himself in their likeness and assimilate himself to them. ${ }^{49}$

I fail to find anything "pathetic" about a person's struggle towards such Truth. As for the developing self-mastery of the philosopher, is it not the case that while the need for fellowship and integration into the practices of a tribe is an essential ingredient, its full status is conditional upon an abiding attunement to the obligation to critically challenge, when necessary, the moral and intellectual practices of our tribe, including those "agreements in judgement" we take to be absolutely 
indispensable to our given practices? Is not the divinization of present and particular practice not itself a threat to the "pattern and order" authentic selfhood requires?

If, indeed, a valid form of liberal education is to have for its primary end the fulfilled existence of the individual and of the community, then I do not think that we should dismiss this conception of the eros of truth as quickly as Cooper seems to want to do here. In a somewhat different vein, I would say that the dialectic of tradition and critique which should support our contemporary formulations of a liberally educated person should proceed within the recognition that the pattern and order of Heidegger's "They" comprises a necessary but hardly sufficient condition for the authenticity of selfhood and of community.

In her well-known essay entitled "Needed: a paradigm for liberal education" $" 50$, Jane Roland Martin inveighed against a plethora of dualisms operative at various levels of explicitness in the early Hirst's theory of liberal education: mind/ body, theory/practice, reason/emotion, knowledge/value, imagination/intellect, $\mathrm{mind} / \mathrm{self}$, vocational/liberal, commitment/detachment, autonomy/community. Here in "Curriculum and the Mirror of Knowledge," Martin addresses some views on liberal education developed by Allan Bloom, E.D. Hirsch Jr., and William Bennet. No doubt because of Hirst's clear denunciation of the view "that a curriculum must or ought to be divided into subjects that mirror distinctions between the forms of knowledge," ${ }^{51}$ Hirst emerges almost completely unscathed this time round. The other writers, however, deemed exemplary "elders in our twentieth century white man's culture," are claimed to explicitly or implicitly trade on the powerful and influential metaphor of the mirror - a metaphor which Martin claims holds much of contemporary curriculum theory and reform captive. (The other historically dominant metaphor, which Martin is silent about, is of course that of the sun understood as the medium within which vision and the visible are enabled and nourished: "... as the Good is to reason and its objects, so is the sun in the visible world to vision and its objects of vision." ${ }^{52}$ Martin argues that our elders' laments over the fragmentation and incompleteness of school and university curriculum, together with their insistent calls for a restoration of a past unity and integration of knowledge, owe their influence to a presumptive picture of the subject-based curriculum as the great mirror of knowledge and, in turn, of knowledge as the mirror of nature itself. For Martin, this is all fantasy and it is all being done with mirrors. Her complaint is that while Rorty's deconstruction of the mirror-metaphor in epistemology has broken asunder the conception of knowledge as a unified integrity constructed upon solid foundations of first principles and reflective of the order of nature itself, writers such as Bloom continue to respond to what they claim 
is "an intellectual crisis of the greatest magnitude, which constitutes the crisis of our civilization" with a yeaming to restore a curriculum able to represent clearly within itself the unity and integrity of socio-historically transcendent truth. ${ }^{53}$ According to Martin, this felt need is inspired by grounds having little coherent force and is actually inimical to both the theory and reform of curriculum. She argues that the contemporary fragmentation of knowledge, comprehended as the absence of any coherent set of first principles to serve as a foundation for an integrated curriculum, entails an inchoate and fragmented curriculum only given the erroneously assumed applicability of the metaphor of curriculum as a mirror of knowledge. ${ }^{54}$ And this, Martin continues, is to commit the epistemological fallacy in education all over again; it is to fail to see that "a reflection of a shattered mirror image will of necessity represent that shattering..." ${ }^{\text {I5 }} \mathrm{I}$ take this to mean that we can find only what we seek, and we seek only that which we in some way already know. The unifying thread running through Martin's analysis is that nothing necessarily follows from the epistemic status or character of knowledge for the curriculum since curriculum is neither necessarily defined nor appropriately assessed by the false measure of the accuracy of its reflection within a mirror of knowledge itself mirroring nature. This should be clear, Martin contends, to all who are able to tear themselves away from the double mirroring here and recognize curriculum's independent possibilities for integration and wholeness. Martin provides examples of such integration and offers an analysis of the ways in which our concepts of "shattered," "pieces," "unity," and "integration" do accurate work when applied to physical mirrors but fail us in our deliberations on curriculum design and reform when seen through the metaphor of the mirror.

The metaphor of the mirror of course played a central role within Michael Oakeshott's now classical but far from uncontested articulation of a liberal education as an education for self-discovery: "[T]here is no other way for a human being to make the most of himself than by learning to recognize himself in the mirror of this inheritance of human achievement." ${ }^{56}$ And such allusions are often to be discerned in Bloom's own writings on the idea of a university and the ideal of liberal education as a quest for human nature in its atemporal character. Martin warns us, however, that such talk can easily lead us to view the curriculum as essentially detached from human purposes and creative imagination. In virtue of its language, we come to see the parts of the mirror (i.e., the disciplines) as being somehow complete unto themselves, having their own fixed essence, and when broken from their whole, requiring to be re-integrated in one way and one way only. ${ }^{57}$ For Martin, mirror talk not only itself produces the logic and rhetoric of 
curricular fragmentation, but also yields "a language of internal relationships" within which our talk of the immanent relationships between subjects and their selforganizing underlying principles precludes the raising of such important external matters as the potentially exclusionist character of a curriculum, its lack of meaning for students, its hesitancy or even refusal to incorporate new knowledge and perspectives into itself, and the moral character of its responses to contemporary social and political matters. Martin argues that only by bracketing "the inward gaze" into the immanent logic and structure of the curriculum, and by denying our elders' "restorative presumption" can we sight the true significance of the absence from the traditional canon of Blacks, women, American Indian cultures, the poor, the dispossessed, together with their respective values, concerns, and pleas. Correlatively, we are empowered to appreciate the value of forms of scholarship such as Third World philosophy, Women's History, and Black Literature which attempt to challenge presently canonized curricular criteria of objectivity and universality. ${ }^{58}$

Perhaps some of the things I have to say above regarding Cooper's essay may also be applicable to Martin's efforts. But the issues and criticisms raised by Martin may also profitably be read in connection with Snook's contribution: "The Curriculum: the Timeless and Time-bound." One finds echoing throughout this essay Oakeshott's pedagogical exortation to the teacher of liberal education "to hold up the mirror of human achievement before a pupil and to hold it in such a manner that it reflects not merely what has caught the fancy of a current generation, but so that it reflects something which approximates more closely to the whole of that inheritance." 59 Snook reflects upon whether criteria for the integration, unity and comprehensiveness of a school curriculum in the tradition of a liberal education somehow require apriori to be subject- or discipline-based; whether an epistemology for the curriculum requires a representationalist, mirroring conception of the relation between disciplines and knowledge; and whether a philosophical anthropology or an ontology of the human for the curriculum requires an image of humans as primarily objective knowers. We are invited by Snook's essay to consider whether creative human agency may not legitimately look to the timeless for guidance in developing and reforming curriculum and whether abandoning the restorative mode of curriculum theorizing may actually be counter-productive to the realization of our own ideals.

For Snook, a major task for curriculum theory, design and reform today is "to reconcile the timeless and the time-bound," and this presupposes being clear about that dimension of our knowledge and practices which is perennial and that 
which is evolving. I read Snook to be saying that the time-bound and contingent is too much with us today in curriculum thinking and, as a result, a recognition of the "timeless" is easily precluded from view. Because curriculum is so amenable to being pushed and pulled by changing political, social, ethical, and biographical agendas, we readily fail to acknowledge that there are indeed perennial "boundaries of curriculum" and "touchstones [for] its adequacy." 60 Snook maintains that the parameters for "the timeless task of educating human beings," for the formation of a curriculum which frees the next generation from the chaos of inheriting a cultural tabula rasa, are ontological and epistemological: "Bounds are set by the nature of the world and by the nature of us as beings-in-the-world."61 ${ }^{16}$ The curriculum is the medium within which the questions we have been asking since the dawn of time, and the "relatively stable answers" which we have been able to give them within our practices and bodies of knowledge, form a genuine heritage in our evolving modes of interrogating and coping with the world. Coherence, integration and comprehensiveness are defined here by what may very well comprise a finite number of ways of being-in-the-world. Snook makes recourse to Aristotle's delineation of three modes of relating to the world and their respective forms of knowledge: the theoretical, the productive, the practical..$^{62}$ One important way of addressing the timeless within curriculum design is to recognize these forms as constitutive of our very nature as humans and to ensure that no one distinctive form be permitted to maintain hegemony over or be reductionistically conflated with either of the others. Gaining clarity on the relationship between curriculum and the forms of knowledge we inhabit requires not mistaking the time-bound for the timeless. This, according to Snook, is the error which epistemologically "absolutist" views of disciplines, sometimes relying on naive realist or empiricist epistemology, make within their construal of disciplines as bodies of eternal verities we have somehow found or "discovered" ready-made in the world. Such views, Snook warns, both reify a living, evolving, disciplinary corpus of knowledge and end up misrepresenting the character and role of our productive abilities and engagements within social practices. Nor should we make the converse mistake of misconstruing the timeless for the time-bound, as is done within versions of idealist epistemologies of the curriculum common to some "Marxist" sociologists of the curriculum which espouse a view of disciplinary forms of knowledge as simply contingent "sociohistorical constructs" possessing no autonomous integrity of their own, thus allowing for total malleability under the curricular hand. ${ }^{63}$ Both views, Snook argues, fail ontologically: "Our situation as humans in the world is bounded by two ontological facts: we have different kinds of interests; and the world has different 
kinds of properties." ${ }^{64}$ Once this is correctly understood, Snook maintains, it makes perfect sense to speak of a "naturally constituted discipline" in Rescher's sense, one which systematizes regularities discovered in the world and upon which the organization and integration of the curriculum may successfully proceed. Snook recognizes that at times disciplinary knowledge is just plain wrong. But this does not speak against the persistence within human evolution of the above three forms of questioning and answering the world, nor against the significant successes of our adaptive capacities and the warranted assertability of our beliefs and knowledgeclaims over the course of time. For Snook, our major questions, the ones serving to fundamentally define who we are, have proven perennial. In the theoretical domain, we interrogate the grounds of our beliefs and understandings; in the practical, we ask the sense of "the good life"; in the productive, we remain concerned about the appraisals of our products and the validity of our ascriptions of ability. It would be a grave mistake, Snook warns, for our theories of curriculum design and practices of reform to end up underestimating the nature and significance of these perennial questions. The essay concludes by drawing some sensible curricular criteria for a unified and comprehensive school curriculum and offers specific examples of subjects which can be studied as respective instances of the three forms of knowing/ questioning/being.

Hirst's position on the roles of morality and religion in the public schools of a liberal democracy is well-known for 1) its strictly secular understanding of the nature and justification of morality as a logically autonomous realm, 2) its strong commitment to the serious ("sophisticated") teaching and preparation of teachers for the teaching of distinctly moral values, reasoning, principles and dispositions, 3) its comprehension of religion as proffering no intrinsic or necessary authoritative resources in matters of moral justification or the quest for the morally good life, and 4) its view that an objective understanding of religion and "religious morality" is in no way being rejected and remains a legitimate part of public education. Rendered in the form of a heuristic equation: religious morality = secular morality + religion (where "religion" is understood to possess some features not incompatible with secular morality). In "Moral and Religious Education: Hirst's Perception of Their Scope and Relationship," Brian Crittenden offers a comprehensive critical review of Hirst's writings on this issue and raises a number of important objections to various conceptual, epistemological and educational aspects of his account. Crittenden concludes on the basis of his own account with a set of conditions for a coherent and justifiable synthesis of moral and religious education.

Crittenden's critical examination of Hirst's views is not without its tensions,

Paideusis 13: 2, 2000 
however. There is agreement with Hirst's position that the rationality of moral judgement and the moral life admits of justification independent of religious considerations and that, indeed, secular rational justification is logically required by any religious perspective. ${ }^{65}$ Crittenden acknowledges, for example, that conceptions of the goodness of God can neither be formulated nor defended apart from our understanding of what constitutes the morally good and our justifications of the latter should be free of question begging. While agreeing with Hirst that religious faith on its own provides no solid ground for moral justification, Crittenden remains wary of Hirst's fidelity to the thesis of the primacy of capacities for theoretical rationality in the moral realm, ${ }^{66}$ draws attention to a number of constricting features of Hirst's understanding of religious meaning and religious life, and raises the possibility that Hirst may have oversimplified the relevance of Divine command within moral obligation. ${ }^{67}$ Crittenden's reticence in accepting some of Hirst's views culminates in the claim that "there is a necessary religious aspect to morality. "68 I find the subscription to this view on Crittenden's part hard to understand given the agreements with Hirst outlined above. Fortunately, Crittenden himself finds this a paradoxical position to be in. Nowhere in the essay do I find it satisfactorily resolved. In clarification, and pace the Hirstian claim that "moral discourse is essentially cognitive at its core," Crittenden points to

elements in morality and related conditions of life that escape the full grasp of knowledge: for example, the mysterious aspects of good and evil that individuals find within themselves and others, of suffering and death, of the existence of the universe beyond the reach of scientific explanation. ${ }^{69}$

This sentiment I find to rest at the heart of the essay; it is from its source that Crittenden objects to the adequacy of Hirst's logical and epistemological apparatus in comprehending and appreciating the above elements of our lives as well as our deeply human experiences of awe, wonder, reverence, and the mystery of personhood underlying the cognitive principles exhorting respect for rational human agency.

On behalf of those Christians who would reject the coherence and adequacy of Hirst's secular morality, together with its "necessary" applicability to their own lives, Crittenden targets Hirst's lack of any serious consideration of the necessary role of divine revelation in the moral life, as developed by Augustine, for example, or of justifications of morality such as are to be found in the writings of Aquinas on natural law. These are offered as instructive examples for Hirst of accounts which do not fallaciously invoke religious beliefs in the premises of arguments concluding with claims about divine being. From an epistemological angle, Crittenden wonders how it is that a conceptual scheme such as Hirst's own secular morality can yield 
objective, testable claims against experience when the very possibility for experience is conditioned by the framework itself. ${ }^{70}$ Epistemological, moral and educational issues dovetail in the argument that Hirst's deployment of epistemic criteria of objectivity relying on publicly agreed-upon practices of verification tend to polarize the public and private features of religious commitment, thereby attenuating standard connections between "private" religious belief and morallyladen public issues - i.e., government funding of abortion and the morality of war. ${ }^{70}$

Hirst is of course aware of this connection between the public and the private. $^{71}$ Whether his account actually does falter on this point I think depends upon the legitimacy of his claims regarding the autonomy of the moral realm, specifically the argument that distinctly moral justification possesses a coherent core of rationally defensible principles, values and dispositions binding upon persons in both the public and private aspects of the moral life. This argument is attempted by Hirst in his Moral education in a secular society. But I have to concur with Crittenden's point that, as things stand at present, any sustained dialectical force on this matter is missing in Hirst's account due to its very thin rendition of Christian religion. ${ }^{72}$ A genuine strength of Crittenden's essay, and one perhaps mitigating its logical anomalies, is an understanding of the Christian religious life transcending Hirst's skeletal conceptions of grace, prayer, ritual and worship, "the ultimate transcendent scheme of things." Even the informed atheist or agnostic reader is able to discern clearly that Crittenden is definitely more fundamentally moved by the Christian mysteries of grace and personhood than by those features of Christianity figuring prominently in Hirst's depictions - i.e., the anachronistic character of attempted applications of Biblical teaching to 20th. century society, views of desire as wicked temptation, conceptions of human nature as naturally corrupt, and an insistence on the necessity of supernatural assistance for a morally good life. On the other hand, the force of Hirst's account must be seen to rest in his outline of the possibility for an autonomous form of secular morality. But there I believe Hirst is vulnerable to many of Critenden's criticisms in that he relies very heavily on an inadequately articulated and thinly defended version of morality provided by R.S. Peters and John Wilson. Such a state of affairs I find odd since Hirst himself repeatedly acknowledges the crucial importance of an adequate justification of the core principles and forms of reasoning making up secular morality ${ }^{73}$ and insists the version he works with is "not just another alternative morality. ${ }^{74}$ The justification of that claim requires much fuller articulation than Hirst has thus far been able to provide. This especially since he views the following claim to be underwritten by it:

Christians must, I think, reconcile themselves fully to the truth that men can

Paideusis 13: 2, 2000 
naturally do morally good actions and that they can live the moral life without the injection into that life of divine, supernatural force, as something over and above the natural operations of the mind. ${ }^{75}$

Hirst's abiding commitment to teaching has been recognized both formally and informally many times. No Festschrift for Hirst would thus be complete without a contribution focussing on the character of the teaching which liberal education attempts to foster. At the end of the day, it is perhaps our practices of teaching which will set the direction and seal the fate of the future of liberal education in our schools and universities. This fate, in my view, rides on the stability of that sole institution, that distinctive "educative site," which makes liberal education its own business. At least it has in the past. Only a university can do that today and the heart of a university is nourished not by the technical-objective exigencies of "instruction and research," but rather by love of inquiry and the practice of good teaching.

Warnock's "Good Teaching" lays out a courageous position on the characteristics and dispositions that make for a good teacher and on the features of schools whose practices and policies can nourish or starve the teacher. Good teaching emanates from a vision of teaching as a practice having its own intrinsic end:

to help people to see the world as intelligible ... and therefore perhaps to see themselves in the world not as mere passengers, carried along by hidden and mysterious forces, but as able to intervene to change things, and to control. ${ }^{76}$

Warnock paints a portrait of the good teacher which cannot but remain invisible within now-standard accounts of "teacher competencies." Good teachers possess a subtle dramaturgical sense of how to present themselves and how to "command attention through the force or uniqueness of their own presence." ${ }^{177}$ One of the characteristics examined is the authority of the teacher, its grounds and manners of appropriate display. Warnock is well aware of our present-day resistances to this term in heralding the teacher as facilitator, enabler, mediator, or some other appellation serving primarily to shield the teacher from feared charges of dogmatism and indoctrination. For Warnock, the good teacher is not only able to teach specific skills and forms of understanding, but is also prepared to reveal her own commitments, her own stands on issues together with the reasons for them.. She is "quite prepared to teach a specific ethos, a preferred way of behaving." ${ }^{78}$ And with this I know Hirst would readily concur.

* This paper has benefitted significantly from criticisms and suggestions offered by Harvey Siegel, William Hare, and Terry Piper. I owe a special debt of gratitude to Michael J.B. Jackson for his many incisive substantive and editorial 
recommendations. All errors remain my own.

\section{Notes and References}

1. Bruce Kimball, in his very comprehensive and fascinating Orators and philosophers: $a$ history of the idea of liberal education (New York: Teachers College Press, 1986), makes the historical case that the philosophical ideal of liberal education that can be traced back to Socrates and Aristotle is but one version of the ideal and that we end up begging the question of what a liberal education is by identifying liberal education with this one strain.

2. Charles Bailey's very finely thought-out Beyond the present and the particular: a theory of liberal education (London: Routledge \& Kegan Paul, 1984) makes the strong claim that it is indeed our moral duty to provide a liberal education within our schools and that the legitimacy of political governance over education rides on the fulfillment of this duty.

3. See Keeney's bibliography of secondary sources on Hirst for an indication of the range of critique.

4. Jonas Soltis, "Review of Knowledge and the curriculum," Teachers College Record, 80, \#4 (May 1979) 774.

5. One version of this debate pursues the question over the generic or disciplinary-specific character of "critical thinking" as an educational ideal. The following are four recent contributions to this debate: Teaching critical thinking: dialogue and dialectic, by John McPeck (New York: Routledge, 1990); The generalizability of critical thinking: multiple perspectives on an educational ideal by Stephen P. Norris, ed. (New York: Teachers College Press, 1992); Educating reason: rationality, critical thinking and education, by Harvey Siegel (New York: Routledge, 1988); selected essays in Siegel's Rationality redeemed? (New York: Routledge, 1997). I have attempted a reconstruction of Siegel's "transcendental" position in "Siegel's transcendental quest," Paideusis: Journal of the Canadian Philosophy of Education Society, volume 11, \#2, Winter 1998, 13-25.

6. See Paul Hirst's Knowledge and the curriculum (London: Routledge \& Kegan Paul, 1974a) and the particularly important "Literature, criticism and the forms of knowledge," Educational Philosophy and Theory, volume 3, 1971, 11-18. Other relevant works are cited by Patrick Keeney in his compilation of works by Hirst in Beyond liberal education.

7. Hirst in Barrow \& White, 197.

8. See John White's Education and the good life: autonomy, altruism, and the national curriculum (New York: Teachers College, Columbia University) 110.

9. Hirst, in Barrow \& White, 197.

10. Ibid, 197-8.

11. Hirst, 1974a, 30.

12. Ibid, 22. There is already a definite tension in the early Hirst's writings between the view that "the cognitive, intellectual life of a person constitutes a core round which other aspects of his life are organized" and the less extreme, more comprehensive view that the forms of knowledge/understanding "[e]ach ... involves distinctive dispositions, emotions, skills [and] roles" which recommend a "concept of education ... concerned with the development of the 
person in every aspect, be this intellect, dispositions, emotions, roles skills. ... The development of the person's reason is therefore central in all areas, but no more the whole story ..." See his Moral education in a secular society (London: University of London Press Ltd, 1974b) 83, 85, 93.

13. Hirst in Barrow \& White, 197.

14. Ibid, 184.

15. Ibid, 191.

16. Ibid, 197.

17. Ibid, 191.

18. Ibid.

19. Ibid.

20. Ibid.

21. Ibid, 192.

22. Ibid, 191.

23. Ibid, 190.

24. Ibid, 189.

25. Ibid, 190.

26. Ibid, 191.

27. Ibid, 197.

28. Onora O'Neill develops this line of thought pace MacIntyre in "Kant after virtue," Inquiry 26, 1984, 387-405.

29. Some recent texts directly relevant to this issue are: Marcia Baron,"The ethics of duty / ethics of virtue debate and its relevance to educational theory," Educational Theory, Spring 1985, Volume 35, \#2, 135-149; John White, Education and the good life: autonomy, altruism, and the National Curriculum, (New York \& London: Teacher's College, Columbia University, 1991) Chapters 2 \& 3; Charles Larmore, "The right and the good" \& "Moral knowledge" in The morals of modernity (Cambridge University press, 1996); Bernard Williams, "Morality, the peculiar institution" in Ethics and the limits of philosophy (Cambridge, Mass.: Harvard University press, 1985) and "Internal and external reasons" in Moral luck (Cambridge: Cambridge University Press, 1981); Nancy Sherman, "Concrete Kantian respect," in Virtue and vice, ed. by Ellen Frankel Paul, Fred D. Miller, Jr., Jeffrey Paul (Cambridge: Cambridge University press, 1998); Jonathan Dancy, Moral reasons (Oxford: Blackwell, 1993; Christine M. Korsgaard, in Creating the kingdom of ends (Cambridge: Cambridge University Press, 1996).

30. Paul Hirst, ed., Educational theory and its foundation disciplines (London: Routledge \& Kegan Paul, 1983).

31. Jean-Francois Lyotard, The postmodern condition: a report on knowledge (Minneapolis: University of Minnesota Press, 1993) 4-5. See Bill Readings, The university in ruins (Cambridge, Mass: Harvard University Press, 1996): "[T]he analogy of production itself must be brought into question: the analogy that makes the University into a bureaucratic apparatus for the production, distribution, and consumption of knowledge." 163. 
32. Michael Joseph Oakeshott, "The study of 'politics' in a university," in Rationalism in politics and other essays (Indianapolis: Liberty Press, 1991) 194. In "The definition of a university," Oakeshott expresses this view quite clearly: "For there is something properly and unavoidably 'cloistered' about a university. Its pursuits have only an oblique relationship to the world in which immediate usefulness is the criterion of importance. It is a luxury - not in the sense that what it supplies is superfluous to all but the very sophisticated, but in the sense that this belongs to the world of human wants rather than to the world of human needs." Journal of Educational Thought, 1, \#3, 1967, 139. I am reminded in this context of the words of Jaroslav Pelikan who writes: "Scholars in all fields, myself included, have often defined the purpose of research as the single-minded pursuit of truth at any price, or almost any price, and have cited the principle of knowledge its own end in justification. But during the twentieth century - partly, it is obvious, as a consequence of the Holocaust, but also as a consequence of more general reflection - it has become clear to all of us that such a definition is both simplistic and dangerous, leading, as it can, to the torture or the pharmacological manipulation of witnesses in order to obtain accurate 'knowledge.' The principle of knowledge its own end, then, must be integrated with a larger and more comprehensive set of first principles, which can be summarized under the heading (likewise Aristotelian) of "intellectual virtues." The idea of the university: a reexamination (New Haven \& London: Yale University Press, 1992).

33. Pring in Barrow \& White, 66.

34. Martha C. Nussbaum, Cultivating humanity: a classical defense of reform in liberal education (Cambridge, Mass: Harvard University press, 1997) 297.

35. Pring in Barrow \& White, 68.

36. Richard S. Peters, "Ambiguities in liberal education and the problem of its content," in Education and the education of teachers (London: Routlegde \& Kegan Paul, 1977)46-67.

37. Ibid, 52.

38. Chandra Mohanty, "'On race and violence: challenges for liberal education in the 1990s," in Education: culture, economy, society, eds., A.H. Halsey, Hugh Lauder, Phillip Brown, Amy Stuart Wells (Oxford: Oxford University press, 1997) 558.

39. Charles Taylor, Sources of the self: the making of the modern identity (Cambridge, Mass: harvard University Press, 1989) See esp. Part III.

40. Cooper in Barrow \& White, 45.

41. Ibid, 46.

42. Ibid.

43. Ibid, 38.

44. Ibid, 37-38.

45. Ilham Dilman, Philosophy and the philosophic life: a study in Plato's Phaedo New York: St. Martin's Press, 1992).

46. Ibid. See especially 100-113.

47. Plato, The Republic in Collected dialogues, Edith Hamilton \& Huntington Cairns, eds. (Princeton: Princeton University Press, 1961) 487a. 
48. Ibid, $519 \mathrm{e}-520 \mathrm{a}$.

49. Ibid, 500c. I believe that Dilman can profitably be read as providing a suitable reply to Cooper's reading of the "fulfilled human existence" that is purportedly grounded by Plato's conception of Truth and the ideal of making contact with it: "The patient man ... can tolerate frustration. He can bear adversity with fortitude, loss without bitterness, injury without resentment, suffering without complaint, injustice without a desire for retribution. He can contemplate beauty without wanting to lay his hands on it, make it his own. That is, he may be hurt, he may grieve, he may suffer, but in his relation to what he cares for, what he believes in, he remains constant, unchanged. ... As such he is outside the fissure of relationships that are 'subject to time' - relationships, that is, that are dependent on contingent circumstances and are themselves directed to control or influence those circumstances" 125.

50. Jane Roland Martin, "Needed: a paradigm for liberal education," in Philosophy and education: eightieth yearbook of the National Society for the Study of Education, Jonas Soltis, ed. (Chicago: University of Chicago press, 1981) 37-59.

51. Hirst, 1974, 140.

52. Plato, 1961, 508b.

53. Martin in Barrow \& White, 109-110.

54. Tbid, 111. For some of the different meanings and uses of Bloom's Platonic notion of "knowing nature," and for the possibility that such "knowledge" may be less a matter of "mirroring" and more one of "being in accordance with," "adhering to," "abiding by," "being true to / committed to, see The Republic of Plato, translated, with notes, interpretive essay and introduction by Allan Bloom (Basic Books, Harper Collins Publishers, 19XX). Especially pp. $321,399,404,409,424,432$. See too note 49 above.

55. Tbid, 112 .

56. Oakeshott, 1967, 132.

57. Martin in Barrow \& White, 112-4.

58. Ibid, 118-9. The view that inclusivist/exclusivist practices are basically political phenomena is today often developed within reformulations of liberal education having for their principal aim the "decolonization" of practices of teaching and inquiry. Mohanty (in Halsey, Lauder, Brown \& Wells, 1997) writes: "Teaching about histories of sexism, imperialism, and homophobia potentially poses very fundamental challenges to the academy and its traditional production of knowledge, since it has often situated Third World peoples as populations whose histories and experiences are deviant, marginal or inessential to the acquisition of knowledge. And this has happened systematically in our disciplines as well as in our pedagogies. Thus the task is to decolonize our disciplinary and pedagogical practices." See in this connection Harvey Siegel, "What price inclusion?" in Siegel 1997, and Martha Nussbaum, "The study of non-western cultures" and "African-American studies" and her identification of four vices a liberal education intent on cultivating humanity needs to avoid ("descriptive chauvinism," "descriptive romanticism," "normative Arcadianism," "normative scepticism") in Nussbaum, 1997. 
59. Oakeshott, 1967, 133. But on the limits of Oakeshott's account pursued in line with some of Martin's views, see K. Williams' "The gift of an interval: Michael Oakeshott's idea of a university education," British Journal of Educational Studies, 37, \#4, 1989, 384-397.

60. For an interesting related attempt to transcend what Plato refers to as "the world of sights and sounds" and glimpse the time-free and culture-free idea of education as a transcendental enterprise, see John Wilson's Preface to the philosophy of education (London: Routledge \& Kegan Paul, 1979) and "Education and transcendental enterprises," Oxford Review of Education, vol. 17, \#3, 1991.

61. Snook in Barrow \& White, 105-6.

62. But see John Dewey's Democracy and education (New York: The Free Press, 1966) for arguments on the historical specificity of Plato's and Aristotle's understanding of theoretical, practical and technical knowledge.

63. Snook in Barrow \& White, 106.

64. Ibid, 97.

65. Crittenden in Barrow \& White, 145.

66. For statements of this thesis see Hirst 1974b, esp. 83, 85, 93, 114.

67. Crittenden in Barrow \& White, 132.

68. Ibid, 148.

69. Ibid.

70. Ibid, 138. On the problem of the extent to which cultural consensus is relevant to the "public agreement" required for objectivity, see "On objectivity and consensus," in Nicholas Rescher's Objectivity: the obligations of impersonal reason (Notre Dame: University of Notre Press, c1997.

71. Hirst 1974b, 54.

72. Ibid, esp. 11, 18, 54-6, 70, 74-5, 78, 84.

73. Ibid, 6, 17-18, 28, 32, 35, 41, 43.

74. Ibid, $12,46$.

75. Ibid, 73.

76. Warnock in Barrow \& White, 21.

77. Ibid.

78. Ibid, 22-3. 